\title{
Les objets sous contrainte. Gages, saisies, confiscation, vol, pillage, recel...
}

Auxerre, table ronde, 20-21 novembre 2009

\section{Laurent Feller}

\section{(2) OpenEdition}

\section{Journals}

Édition électronique

URL : https://journals.openedition.org/cem/11115

DOI : $10.4000 /$ cem. 11115

ISSN : 1954-3093

Éditeur

Centre d'études médiévales Saint-Germain d'Auxerre

Édition imprimée

Date de publication : 15 août 2009

Pagination : 345-347

ISSN : 1623-5770

\section{Référence électronique}

Laurent Feller, «Les objets sous contrainte. Gages, saisies, confiscation, vol, pillage, recel... », Bulletin du centre d'études médiévales d'Auxerre | BUCEMA [En ligne], 13 | 2009, mis en ligne le 04 septembre 2009, consulté le 22 septembre 2022. URL : http://journals.openedition.org/cem/11115; DOI : https:// doi.org/10.4000/cem. 11115

Ce document a été généré automatiquement le 22 septembre 2022.

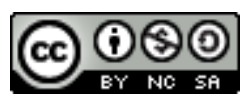

Creative Commons - Attribution - Pas d'Utilisation Commerciale - Partage dans les Mêmes Conditions 4.0 International - CC BY-NC-SA 4.0

https://creativecommons.org/licenses/by-nc-sa/4.0/ 


\section{Les objets sous contrainte. Gages, saisies, confiscation, vol, pillage, recel...}

Auxerre, table ronde, 20-21 novembre 2009

\section{Laurent Feller}

Cette table ronde s'inscrit dans le cadre d'une réflexion menée sur la valeur des choses au Moyen Âge, c'est-à-dire sur les conditions empiriques et théoriques de l'évaluation ; un groupe de travail conjoint du LAMOP (UMR 8589, Paris 1-CNRS) et du CSIC de Madrid organise une série de tables rondes. La première s'est tenue à Madrid en novembre 2008 et a eu comme thème : "Circulation et remploi des objets au Moyen Âge ».

Les objets circulent parfois malgré la volonté de leurs propriétaires, en quelque sorte malgré eux, aussi. Le but de la réunion que nous organisons est d'étudier la mise en circulation des objets sous contrainte, c'est-à-dire de voir dans quelles conditions et dans quelles circonstances les personnes peuvent être dépossédées et leurs biens mobilisés à d'autres fins que celles qu'ils leur avaient d'abord assignées, c'est-à-dire cesser de satisfaire à leurs besoins propres pour servir à autre chose. Cette réflexion s'inscrit dans le prolongement de la table ronde menée à Madrid en novembre 2008, puisque c'est encore du changement de statut des biens matériels qu'il s'agit.

On entend ici par gages non pas les choses liées à des personnes situées dans des interactions sociales, mais les objets liés à des individus pris dans des processus économiques. On désire donc, cette fois, s'interroger sur la façon dont les biens circulent en dehors des relations interpersonnelles, mais en dehors aussi du fonctionnement normal du marché et de ses institutions ou, plutôt, parallèlement à celui-ci. Les biens en question, soustraits à leur possesseur originel par des processus économiques - la mise en gage pour obtenir un prêt -, légaux - la saisie ou la confiscation - ou de pure violence - le pillage, le vol, suivi de recel -, sont tantôt immobilisés, tantôt jetés sur le marché, dans des conditions qui les transforment de nouveau. Les biens confisqués cédés à vil prix à des amis ou à des gens que l'on veut obliger; les objets mis en gage vendus en dessous de leur valeur vénale telle qu'elle 
pourrait se mesurer sur le marché ; les objets volés et recélés cédés à la fin à bas prix sont le témoignage de l'existence de phases alternées de mobilisation et d'immobilisation qui correspondent à des changements de statut, opérés par un travail rituel fait lors de la mise en vente : il faut alors procéder à un ensemble de gestes qui permettent la formation d'un prix et trouver les gestes qui formalisent l'échange.

Plusieurs types de contraintes peuvent être signalés :

- contraintes sociales. La mobilisation des objets est parfois liée à des formes de contrôle social opérées sur certains types de populations. Par exemple, dans le Vallespir du $\mathrm{XV}$ siècle, les producteurs de fer basques, très mobiles et sans crédit, doivent solder leurs transactions en fer. La monnaie n'est pas ici mobilisée, parce que la contrepartie dans l'échange apparaît comme une modalité du contrôle social et que la transaction, dès lors, n'apparaît que partiellement marchande. On classera aussi sous cette rubrique les règles présidant à la circulation de certains types d'objets, par exemple les bijoux à l'intérieur d'une famille. La question des objets constituant la dot fait aussi partie de la question. On s'efforcera d'approcher également la question du gage dans l'échange. Le gage est en effet ce qui lie et permet de nouer une relation entre deux parties. Il établit une relation interpersonnelle ou en atteste l'existence et sa cession est liée à des rituels ;

- contraintes économiques et juridiques. Ce sont celles qui amènent à se séparer de biens meubles pour en obtenir une contrepartie monétaire sans toutefois en perdre la propriété. L'objet cédé peut ainsi être le garant de la somme empruntée et son destin peut être alors la vente à l'encan, la mise aux enchères. La contrainte doit donc ici s'entendre comme une menace, la perte de tout droit sur la chose cédée en cas de mauvaises affaires; elle s'opère cependant selon des règles et entraîne l'apparition d'obligations. Les saisies ont la même signification. Elles constituent une menace parfois devenue réalité lorsque l'objet est mis à l'encan. Elles ne brisent pas le lien de propriété et ne semblent pas transformer le statut de ce qui est alors mis en circulation. Ces formes de contrainte font ici s'approcher l'ordre juridique de l'ordre économique ;

- contraintes physiques. On entre là dans un autre ordre, celui de la guerre et du pillage, de la prise du butin et de sa redistribution, soit par la vente sous le marché, soit par sa restitution, contre compensations aux propriétaires, soit encore sa thésaurisation. Il s'agit alors non plus de s'interroger sur les formes de l'échange mais des conséquences de formes brutales de dépossession sur le statut des objets concernés.

L'idée est donc d'étudier la façon dont on remet en circulation des objets qui ont au préalable été détournés soit de leur fonction normale par une immobilisation - objets liturgiques ou armes mis en gage - soit au contraire été brusquement ôtés à leurs propriétaires puis revendus ou donnés. Il sera nécessaire de tenir compte, dans toute la réflexion, de la distinction entre ce qui établit des relations interpersonnelles, et qui renvoie davantage à la catégorie des «choses " parce qu'elles attestent d'événements singuliers renvoyant à l'histoire des personnes, et ce qui relève d'interaction purement commerciale entre individus, et qui concerne alors des « objets ». 
INDEX

Mots-clés : gage, saisie, confiscation, vol 